\title{
Formation of readiness for team work of students of the university for humanities in the process of professional training
}

\author{
L.V. Bura ${ }^{1 *}$, E.I. Artamonova ${ }^{2}$, and I.V. Gerlakh ${ }^{3}$ \\ ${ }^{1}$ V.I. Vernadsky Crimean Federal University, Simferopol, Russia \\ ${ }^{2}$ State Educational Institution of Higher Education of the Moscow Region of the Moscow Region \\ State University, Mytischi, Russia \\ ${ }^{3}$ Armavir State Pedagogical University, Armavir, Russia
}

\begin{abstract}
The article covers issues related to the professional training of students of the Humanities, their development and formation of professional culture during this training. In addition, the key problematic aspects related to the system of such education are identified, and various mechanisms for activating and involving students of the Humanities in the process of obtaining the necessary competencies are identified. The key mechanism for this activation was chosen a team-building technology, in accordance with the basic principles of which it is possible to maximize the motivational component of the process of acquiring professional competence. In addition, separate elements of the definition of "readiness" are considered, and the levels of readiness for teamwork among students of higher education are determined. The article is supplemented with a practical part in the form of the results of a survey conducted on the basis of leading universities of the Republic of Crimea in 2020. The subject of the study was to identify the General readiness of students of the Humanities to carry out team activities in order to achieve a common result. The survey was conducted in various areas: readiness to carry out collective and individual creative, project, educational, extracurricular and independent activities. The respondents were teachers of the Humanities who have extensive experience in the organization and management of educational activities in a modern University for humanities.
\end{abstract}

\section{A problem statement}

The labor market, which is rapidly developing in accordance with international trends that prevail in various fields of knowledge and activity, dictates new requirements that arise for graduates of higher educational institutions, and, accordingly, for their professional training [7]. Now it is not enough to be a good specialist - you need to master both professional general and special competencies, a certain set of communicative and creative qualities,

${ }^{*}$ Corresponding author: ipcs-profped@yandex.ru 
personal spiritual development, etc. All this together is the basis of the modern labor market today and is a mandatory tool for effective professional activity [3]. At the moment, in the field of humanitarian knowledge, specialists who are able to carry out their activities in a team as effectively as possible are becoming more and more in demand, since collective activity is recognized as one of the most effective in professional terms.

Team work today is not perceived as exclusively production capacity, but is considered as a certain creative potential, which can be shown only in the case of close cooperation of all subjects involved in the development of the project or in the implementation of joint activities. Collective activity involves the ability to coordinate, negotiate, maintain a relatively high pace of work, as well as understand other subjects of collective interaction, solve tasks and problems set and arising in the process of implementation, and, most importantly, be aimed at achieving a goal that is common to all [16]. In this regard, it would be fair to note the regular search in the system for developing the latest areas of modernization of the higher professional education system, one of which today may be the technology of team building, as well as the technology of active teamwork.

\subsection{The objective of the work}

Today, in modern pedagogical science, a lot of research has found its place in the field of formation of readiness for team work of students not only in the humanities, but also in technical fields, as part of professional training. In our opinion, today the problem of organizing team activities is described in sufficient detail in theoretical studies, but not in practical ones. This study was created with the purpose of adding to the database of practical data on the implementation of team work of modern students.

However, we cannot ignore the work of some Russian researchers who have formed a certain theoretical potential necessary for the gradual development of a system of effective team interaction between the subjects of the educational process. As fundamental theoretical research in the framework of this study, the works of such domestic and foreign authors as M.S. Vasechkina, T.P. Galkina, Yu.M. Gibadullina, I.I. Cherkasova, E.K. Gitman, R.L. Daft, O.B. Dutchina, O.A. Zherebnenko, G.V. Lopatenkov and others, L.I. Savva, E.A. Gasanenko, K.E. Shakhmaeva, V.A. Krutetskiy, A.D. Malysheva, A.A. Orlov, A.V. Gutkin and others.

\section{Materials and the results of the research}

The aim of the investigation was appropriate and thorough consideration of essence and specifics of formation of readiness in students of humanities university to a team work in terms of professional training.

Research objectives:

- to determine the essence and content of the definition "readiness for teamwork of students of the University for humanities in the process of professional training";

- to review the experience of predecessors and compare it with modern realities in relation to the structural and functional model of formation of readiness for teamwork of students of the University for humanities;

- justify and test the degree of readiness for teamwork of students of the University for humanities during the experiment (by means of a questionnaire).

The structure of modern education requires strict and purposeful modernization, which can be achieved exclusively through the use of team technologies [14]. At the same time, it is important to review the mechanisms of influence on students through the use of such technology, since they remain the basis of the educational process, in accordance with the principle of personality-oriented education. In addition, it is important to update the role of 
higher professional education, additional professional education, and secondary professional education in a rapidly developing socio-cultural space, in which modern young people significantly devalue the role and place that educational technologies occupy in the life of modern society [1].

As it was mentioned above, one of the key tasks of modern higher professional education today seems to us to be the formation of the readiness of a future specialist in the Humanities to carry out collective activities in combination with other subjects of the educational process. It is necessary to understand that the modern education system sets itself the task not only to form this readiness, but also to increase its level [15]. The ability to work in a team as a whole is a key criterion that today in most developed countries forms the human resources potential of each individual company and the state as a whole. This is what we think it is necessary to focus on when training modern young professionals to replenish of the human resources potential of the labor market [17].

Before starting to identify the specifics of team activity in higher university, let's consider the definition of "readiness for something", since it is the basis of this research. It is necessary not only to understand the specifics of this term, but also to understand its role in the system of teamwork in the conditions of professional training in higher education.

Readiness in general is a special category of pedagogical knowledge, which is an integrative education of an individual, allowing him to carry out a particular activity depending on external and internal factors [13]. Readiness is always focused on achieving success, positive results, because they provide the motivational "background" of the phenomenon of psychological readiness. In our opinion, readiness is a purely psychological factor, something akin to motivation and involvement of a person in the process of any activity. That is why we are now considering the topic of readiness for teamwork, but not for its direct organization [9].

It is not enough for a modern teacher just to point out the subject of design to students and combine them into thoughtless groups. Such an approach would mean that the teacher himself is not ready to carry out pedagogical activities. It is important to clearly distinguish between the psychological and all other components of the phenomenon of readiness, since this will maximize the effect of joint activities. Young people are extremely vulnerable subjects. They are under regular stress while studying, passing exams, and preparing for project defense. This fact should always be kept in mind before attempting to combine all students into random project teams. Successful teamwork is possible only in the case of a high-quality pre-formed set of pedagogical conditions for the favorable functioning of students [11].

However, it should not be assumed that readiness for teamwork depends solely on the teacher and other external factors. It is important for students to be able to function correctly and clearly and establish interpersonal communication, interact with other subjects of the educational process not only on the communicative, but also on the intellectual and emotional levels. Students should have developed a set of skills that ensure the harmonious development of readiness for team activity [19]:

- the ability to clearly and concisely express your own thoughts, opinions, and positions, depending on the situation and the relevance of this expression;

- freely find expression of your emotions and feelings;

- the ability to either initially avoid a conflict situation that can undermine the emotional state, or prevent it at the most appropriate time;

- have active listening skills and observe communication etiquette;

- empathic and sensory skills in understanding the psychology of the interlocutor;

- ability to ask questions in a timely manner and solve problems that arise;

- skills of active interaction with other subjects of the educational process; 
- the ability to carry out their activities in accordance with the selected (or provided) team role, etc.

All of the above aspects are quite easy to learn from students of humanities related directly to communication, language, speaking, etc. At the same time, it is important to remember that you need to develop intellectual abilities such as eloquence, oratorical skills, etc. $[4 ; 8 ; 10 ; 11 ; 15]$.

Thus, the formation of readiness for team work of students of the University for humanitiesin the process of professional training is an integrative structure that contains many communicative, psychological, linguistic, intellectual and personal aspects. This integration is usually manifested in all areas of a student's life: in work, study, friendship, relationships with colleagues, etc. Therefore, teachers today face the task of paying a significant amount of attention to this particular area of development of the communicative and professional culture of a student of the humanities [17].

Another important element of the readiness system is the motivational structure of the individual. Motivation is the most important engine of development of systems of selfeducation and self-improvement of each modern specialist [6]. It allows you to talk about interests, hobbies, professional and personal goals, it is the basis of success. To form a positive motivation aimed at forming readiness for team work of students of humanities, a modern teacher of a University for humanitiesneeds to learn how to find an active application of all possible pedagogical technologies, resources and tools, in accordance with which the most correct and holistic development of the communicative and professional culture of the individual is possible.

Based on all the above, we can conclude that the process of forming readiness for team activity of students of a University for humanities in the course of professional training is complicated by a mass of internal and external factors that can significantly slow down the development of professional and communication skills of a humanitarian specialist. In general, the system of pedagogical educational conditions that should be used in the implementation of students' team activities can provide extremely effective functioning of various models implemented in it. In our opinion, such a system consists of [13]:

- complex skills learners' diagnostic character required to study their personality, their characteristics, the specific characteristics inherent habits, as well as to effectively identify their own place in the system of team roles and relationships in General;

- a set of specific techniques and methods of teamwork that involve the active use of interactive and innovative methods of teaching and establishing mutual communication with other subjects of the educational process;

- an established system of personal experience in the field of team interaction, which is developed in accordance with the creation and development of projects by students (including course and diploma projects).

In addition, in the study of this topic, we find it particularly relevant to consider the criteria for the level of formation of students' readiness for team activity. These criteria are the basis of the survey conducted by us in order to supplement the theoretical and practical base of the study of the phenomenon of teamwork in higher education. The main criteria for today are:

- communicative criteria;

- interactive criteria;

- professional criteria [2].

The first of the highlighted aspects is the development of the communicative abilities of the student of University for humanities. In the course of its development, the student actively develops the ability to correctly construct speech, to persuade and partially manipulate. In addition, the student's leadership skills in managing and organizing joint activities are also being developed. The student may not always strive for leadership, but 
team management skills should be in any case, because they will not always come across simple team roles.

The second, interactive, criterion is based on the inner world of the student and their ability to carry out interpersonal communication, taking into account the needs and needs of the interlocutors. Here it is customary to pay special attention to empathy, since it is one of the fundamental feelings of a person as a whole. On its basis develop other important qualities according to the type of tolerance, respect, mercy, etc. All these aspects occupy a special place in the system of interpersonal relationships between students of the Humanities [8].

The last criterion applies directly to the student's professional and educational activities. Here it would be fair to mention the formed professional culture and the ability to demonstrate professional skills and abilities. Professional culture, as you know, is formed on the basis of many factors that are both personal, communicative, and profile. It is necessary not just to be aware of yourself in the structure of working relationships and to interact correctly with colleagues. In our opinion, such a culture reveals the maximum professional capabilities of a person, since it contains a lot of aspects [5]. On its basis, professional skills are developed, the demonstration of which is necessary in the organization of teamwork to indicate their place and importance in the system of interpersonal relationships. In addition, this is necessary so that other participants in this process have an understanding of each other's capabilities, which greatly facilitates the process of allocating team roles and responsibilities.

Based on all of the above, we can conclude that teamwork is an objectively complex and energy-consuming field of activity for modern students. In order to look more deeply at the specifics of the process of forming readiness for such activities, it seems most relevant and logical to pay attention to the data in table 1, which illustrates the degree of readiness of students of University for humanities to carry out various types of activities (column on the left). Recall that the survey was conducted by teachers who have some experience in organizing and managing students' teamwork.

Table 1. Assessment of the degree of readiness of students in the Humanities for teamwork in the process of professional training (\%).

\begin{tabular}{|l|c|c|c|c|}
\hline & $\begin{array}{c}\text { Absolute } \\
\text { readiness }\end{array}$ & $\begin{array}{c}\text { Partial } \\
\text { readiness }\end{array}$ & $\begin{array}{c}\text { Partial } \\
\text { unavailability }\end{array}$ & $\begin{array}{c}\text { Absolute } \\
\text { reluctance }\end{array}$ \\
\hline $\begin{array}{l}\text { Implementation of training } \\
\text { activities }\end{array}$ & 12,9 & $\mathbf{4 6 , 3}$ & 24,5 & 16,3 \\
\hline $\begin{array}{l}\text { The implementation of } \\
\text { extracurricular activities }\end{array}$ & 36,7 & $\mathbf{4 1 , 9}$ & 14 & 7,4 \\
\hline $\begin{array}{l}\text { Organization and } \\
\text { implementation of } \\
\text { independent activities }\end{array}$ & $\mathbf{3 5 , 6}$ & 29,1 & 17,2 & 18,1 \\
\hline $\begin{array}{l}\text { Implementation of creative } \\
\text { individual activities }\end{array}$ & $\mathbf{6 3 , 5}$ & 14,7 & 3,6 & 18,2 \\
\hline $\begin{array}{l}\text { Implementation of creative } \\
\text { collective activities }\end{array}$ & 1 & 15,2 & $\mathbf{6 3 , 5}$ & 20,3 \\
\hline $\begin{array}{l}\text { Implementation of } \\
\text { collective project activities }\end{array}$ & 14,7 & 27,3 & 15,4 & $\mathbf{4 2 , 6}$ \\
\hline $\begin{array}{l}\text { Implementation of } \\
\text { collective training } \\
\text { activities }\end{array}$ & 23,4 & 21,6 & $\mathbf{3 3 , 3}$ & 21,7 \\
\hline
\end{tabular}

As it can be seen from the table, the degree of readiness of students for various types of activities varies depending on the form and type. Students were fully or partially prepared 
for individual academic (59.2\%), individual extracurricular (78.6 \%), independent (64.7\%) and creative individual activities $(78.2 \%)$.

These data allow us to conclude that students today prefer individual, independent activities. They are ready to perform tasks of the educational, creative, and project plan independently, without involving additional people.

Many researchers associate this phenomenon with the development of remote technologies that encourage a person's conditional alienation from society (although the whole society is active users of these technologies), and also form a culture of independence in which it is difficult for young people not only to interact, but even to ask for help, provide it, identify problem situations in the activities of an outsider, etc. Thus, a global culture of independent activity and alienation of young people from real social interaction in the real world is being formed.

This is also confirmed by other data, according to which modern students of University for humanities(whose activities are directly related to people and communication) were not ready to carry out creative collective $(83.8 \%)$, project collective $(58 \%)$ and educational collective activities $(60.4 \%)$. Young people are now used to distance learning, remote communication, and a solitary lifestyle.

It is impossible to say with certainty whether this is a positive or negative moment, but there is still a negative phenomenon: the entire range of professional and communication abilities of a person "stiffens" and becomes on the path of degradation. In this regard, modern teachers face an important task in the field of activating and motivating students to collective activities, encouraging them to master communication skills and develop personal, creative and professional abilities.

\section{Conclusions}

Concluding this research, we would like to draw attention to the thesis that was present at the very beginning: the formation of readiness for teamwork of students of the University for Humanities in the process of professional training is a special integrative structure that contains many communicative, psychological, linguistic, intellectual and personal aspects. Knowing this, a range of opportunities is formed, taking into account which, teachers will be able to maximize the impact of team activities and motivate students to various types of work.

The development of the topic of communication skills of modern students of the University for Humanities today is a leading area of pedagogical practice. In this regard, this research can help to implement a larger and global scientific search for solutions to the problem of forming readiness for teamwork of students of the Humanities University in the process of professional training.

\section{References}

1. M.S. Vasechkina, Active training methods: forms and goals of application, 53 (2017)

2. T.P. Galkina, Sociology of management: from group to team: textbook, 224 (2003)

3. Yu.M. Gibadullina, I.I. Cherkasova, Development of social activity of a student in the educational process of a University, Pedagogy and psychology in the integrated space of science and practice: Materials of the $X$ All-Russian (with international participation) scientific and practical conference, 70-75 (2016)

4. E.K. Gitman, Concentrated training in the system of higher military professional education, 4 (2015) 
5. O.B. Dutchina, Psychological conditions and means of developing a positive Selfconcept of a student's personality, 96-99 (dis. PhD in psychology, 2004)

6. O.A. Zherebnenko, Socio-psychological features of the development of the image of a University student, 177 (dis. PhD in psychology, 2008)

7. E.V. Ignatieva, Yu.V. Ryabkova, Relevance of mentoring implementation in the system of higher pedagogical education, Problems of modern pedagogical education, 57 (2017)

8. A.A. Izvolskaya, Independent work of first-year students as a factor of adaptation to training in a pedagogical University, Designing and organizing students' independent work in the context of a competence-based approach. Interuniversity collection of scientific works, 2 (2014)

9. A.V. Zhootkin, Managerial and organizational problems of an effective team in project activity (Author's abstract. dis. 2003)

10. V.A. Krutetsky, Individual features of human thinking, 352 (1980)

11. G.V. Lopatenkov, Formation of students' ability to work in a team in the process of training of bank specialists, 192 (dis. PhD of pedagogics 1999)

12. A.D. Malysheva, Formation of readiness to work in a team of bilingual students (on the example of the Republic of Sakha (Yakutia), 4 (2018)

13. Yu.V. Mikhailova, Methods of forming the competence "readiness to work in a team" in the process of teaching students a foreign language (dis., 2014)

14. V.S. Okuneva, Model of formation of student' competence to work in a team in professional education, Modern problems of science and education, 5 (2013)

15. V.S. Okuneva, Formation of competence of team work of University students, 252 (dissertation, 2013)

16. L.P. Panova, E.N. Raschikulina, L.V. Pavlova, Logical and epistemological bases of forming skills to solve problems in students of higher educational institutions, Pedagogical journal, 1 (2018)

17. E.S. Polat, New pedagogical and information technologies in the education system, 272 (2009)

18. L.I. Savva, E.A. Gasanenko, K.E. Shakhmayeva, Readiness of technical University students to team work as the basis of professional image, 6 (2018) 